\title{
Correlation of Glasgow Prognostic Score or Procalcitonin to Clinical Variables in Patients with Pretreatment Lung Cancer
}

\author{
Young Kim¹, Ji-Yoon Seok ${ }^{2}$, Kyung-Yae Hyun ${ }^{3}$, Gil-Hyun Lee ${ }^{3}$ and Seok-Cheol Choi ${ }^{1, \dagger}$ \\ ${ }^{I}$ Department of Clinical Laboratory Science, College of Health Sciences, Catholic University of Pusan, \\ Busan 46252, Korea \\ ${ }^{2}$ Department of Clinical Pathology, Sorabol College, Gyeongju 38063, Korea \\ ${ }^{3}$ Department of Clinical Laboratory Science, College of Nursing \& Healthcare Sciences, \\ Dong-Eui University, Busan 47340, Korea
}

\begin{abstract}
Unfortunately, the five-year survival rate of lung cancer is relatively low compared with other cancers. Therefore, better predictors are need for prognosis, therapeutic strategy, risk stratification and predicting long-term mortality of lung cancer. Recently, increasing data suggest that Glasgow Prognostic Score (GPS) and procalcitonin levels are useful predictor cancer prognosis. In this study, we retrospectively investigated the correlation of GPS or procalcitonin to clinical variables in patients with pretreatment lung cancer. In 135 patients with pretreatment lung cancer, GPS, procalcitonin, demographic characteristics, hematological, coagulation, biochemical, inflammatory and cardiac markers were measured. Monocyte, eosinophil, basophil, neutrophil to lymphocyte ratio, red cell distribution width (RDW), platelet to lymphocyte ratio, mean platelet volume to platecrit ratio, D-dimer and prothrombin time (PT) levels were higher, whereas mean platelet volume was lower than their normal ranges. Glucose and sodium levels were low, whereas gamma glutamyl transferase (GGT), total bilirubin, creatinine and inorganic phosphorus concentrations were increase compared their normal ranges. Procalcitonin, high sensitivity C-reactive protein and troponin-I concentrations were elevated compared with their normal ranges. GPS had significantly positive or negative relations to cancer stage, hematological, coagulation, biochemical, inflammatory and troponin-I. Based on the data, we suggest that GPS may be a potent and useful predictor for prognosis, therapeutic strategy, risk stratification and predicting long-term mortality of lung cancer.
\end{abstract}

Key Words: Lung cancer, GPS, Procalcitonin, Hematological variable, Biochemical variable

\section{IINTRODUCTION}

Cancer remains the leading cause of death worldwide in individuals aged $60 \sim 70$ years. Lung cancer is especially difficult to detect early and treat and thus has been considered as a major life-threatening malignancy. It is estimated that lung cancer is diagnosed in about 1.8 million patients and causes more than 1.5 million deaths each year (Fitzmaurice et al., 2015). Studies by Jung et al. (2015) showed that lung cancer incidences in Korea were 61.0/100,000 men and 26.8/100,000 women in 2012. Also, based on the National Cancer Center in the Republic of Korea reported that lung cancer incidence rate is $13.8 \%$ in males and $6.1 \%$ in

\footnotetext{
* Received: March 22, 2016 / Revised: April 2, 2016 / Accepted: April 2, 2016

${ }^{\dagger}$ Corresponding author: Seok-Cheol Choi. Department of Clinical Laboratory Science College of Health Sciences Catholic University of Pusan Busan 46252, Korea.

Tel: +82-51-510-0564, Fax: +82-51-510-0568, e-mail: scchoi@cup.ac.kr

(C) The Korean Society for Biomedical Laboratory Sciences. All rights reserved.

(c) This is an Open Access article distributed under the terms of the Creative Commons Attribution Non-Commercial License (http://creativecommons.org/licenses/by-nc/3.0/) which permits unrestricted non-commercial use, distribution, and reproduction in any medium, provided the original work is properly cited.
} 
females, respectively (http://www.cancer.go.kr/mb). Approximately $85 \%$ of lung cancer is due to the effects of smoking followed by genetic factors, radon gas, particulate matter, asbestos and air pollution exposure (Shackelford et al., 2014). The types of lung cancer include non-small cell carcinoma and small cell carcinoma that account for approximately $80 \%$ and $10 \sim 20 \%$ of the total cases, respectively. Unfortunately, despite recent advances in lung cancer research and the use of novel therapeutic agents for lung cancers, the five-year survival rate of lung cancer is relatively low compared with other cancers and remains as low as about 15\% (http://www.cancer.org/) (Siegel et al., 2013). Therefore, development of useful biomarkers or indices may be need for evaluating and predicting risk stratification and longterm mortality of lung cancer.

Recently, accumulated data have shown that host inflammatory responses play an important role in the development and progression of cancer (Lee et al., 2015; McDonald et al., 2009; Tenesa et al., 2010). Especially, C-reactive protein (CRP) or high sensitivity CRP (hs-CRP) levels combined with albumin concentrations (termed the Glasgow Prognostic Score, GPS) had been considered as markers of inflammation and a predictor of cancer-associated survival period (McMillan, 2013). The mortality with cancer is elevated in proportion to increased GPS (McMillan, 2013; Proctor et al., 2013). In addition, Rast et al. (2015) demonstrated that procalcitonin (PCT) improves GPS for outcome prediction in emergency patients with cancer. CRP and PCT have been used as markers to identify sepsis in surgical departments. C-reactive protein levels on postoperative day $3 \sim 5$ have been shown to provide valuable information with regards to the risk of anastomotic leakage (Singh et al., 2014). However, elevated PCT levels emerge before compared with CRP in inflammatory period.

PCT, specific markers for infections, was first introduced in medical literature in 1975 (Dumache et al., 2015). PCT is a 116-amino acid prohormone of calcitonin (CT) and is produced mainly by $\mathrm{C}$-cells of the thyroid gland. It has a molecular weight of $13 \mathrm{kDa}$ (Liu et al., 2015). In healthy state or in the absence of infections, PCT levels in the blood is very low $(<0.1 \mathrm{ng} / \mathrm{mL})$. In case of infection, this protein is synthesized in liver, lung, kidney, intestine, and almost all other tissues throughout the body. Physiological and inflammatory PCT is coded by the same CALC-I gene, located on chromosome 11. A recent report hypothesized that sepsisassociated increase of PCT is mediated by stimulus-specific factors within the promoter of this gene (Liu et al., 2015). The inflammatory PCT is proteolytic cleaved by neither intracellular nor plasma enzymes. So if PCT is secreted into the circulation, it remains there unchanged with a half-life of 25 30 hours. For this reason, PCT has been termed as a hormokine. The production of PCT during inflammation can be induced by the bacterial endotoxin of gram-negative bacteria or by proinflammatory cytokines (eg, IL-1 and IL-6 or TNF $\alpha$ ) (Maruna et al., 2000). The clinical interpretation of elevated PCT concentration in blood represents a great challenge in cancer patients since its values might be influenced by several factors such as the presence of metastasis or neuroendocrine function of malignant tissue (eg, small-cell lung cancer). In these cases, PCT concentrations can be elevated regardless of infections, manifesting a poor specificity for bacterial infection (Patout et al., 2014).

PCT and CT levels are also elevated in patients with medullary thyroid cancer (MTC), and both these proteins are considered to be markers for this disease. A significant correlation between CT and PCT has been observed in patients with MTC but not in infections. In contrast to CT, PCT is more stable and specific in both serum and plasma. PCT measurement is cheaper and more easily available in many hospital laboratories, so it is a good alternative to CT measurement for the management of patients with MTC (Kaczka et al., 2012). Reported PCT levels in patients with generalized metastatic disease are inconsistent. Matzaraki et al. (2007) indicated that patients with solid tumors, metastasis, and no evidence of infection had markedly elevated PCT levels, especially those with generalized metastatic disease. The authors suggested that PCT may serve as an early marker for the progression of neoplastic disease (Matzaraki et al., 2007). However, these findings were in contrast to the report of Giovanella et al. (2010) who demonstrated that solid carcinoma at different stages "per se" did not result in elevated circulating PCT concentrations above $0.5 \mathrm{ng} / \mathrm{mL}$. They were examined in a population of 390 aseptic patients with breast, head and neck, ovary, cervix, and 
non-small-cell lung carcinoma, with or without metastasis. Furthermore, there were few studies for explaining a relationship between GPS and PCT. Therefore, in this study we investigated to clarify the relationship between GPS and PCT in patients with pretreatment lung cancer.

\section{MATERIALS AND METHODS}

\section{Patient population and Glasgow Prognostic Score}

From 2010 January to 2015 May, this study was retrospectively performed in 135 adult patients (30 70 years of age) with pretreatment or non-surgical lung cancer at 'A' hospital located in Busan. The demographic characteristics of study population (gender, age, cancer stage, body weight) are displayed in Table 1. This study was approved by both the Institutional Review Board of Catholic University of Pusan and 'A' hospital. All patients gave prior consent to this study. Glasgow Prognostic Score (GPS) was defined by serum albumin and high sensitivity C-reactive protein (hsCRP) levels (Table 2).

\section{Hematological analysis and blood coagulation test}

$3 \mathrm{~mL}$ of the patient's blood was poured into ethylenediamine tetraacetic acid (EDTA) tube for measuring CBC (complete blood cell count) with Hematology Analyzer (BC-2800 ver., Shenzhen Mindary Bio-Medical Electronics Co., Ltd., Germany). The prothrombin time (PT), activated partial thromboplastin time (aPTT) and D-dimer levels were analyzed by CA-7000 (SYSMEX, Japan) with percentage point detection method.

\section{Biochemical analysis}

The isolated sera of the study population were used for measuring total protein, albumin, glucose, aspartate aminotransferase (AST), alanine aminotransferase (ALT), alkaline phosphatase (ALP), total bilirubin, blood urea nitrogen (BUN), creatinine, uric acid, inorgarnic phosphorus, sodium and potassium concentrations by Autohumalyzer 9005 (Human Lab., Germany). Inflammatory biomarkers (procalcitonin, ha-CRP, amylase, and lipase) and cardiac biomarkers [lactic dehydrogenase (LDH), brain natriuretic peptide (BNP), and troponin-I (TNI)] markers were measured
Table 1. Demographic characteristics of study population

\begin{tabular}{lcr}
\hline \multicolumn{1}{c}{ Variable } & Mean & SD \\
\hline Total number $(\mathrm{n})$ & 135 & \\
Gender $(\mathrm{M}: \mathrm{F})$ & $108: 27$ & \\
Cancer stage & 3.07 & 1.09 \\
Age (years) & 57.21 & 15.76 \\
Body weight $(\mathrm{kg})$ & 66.30 & 15.97 \\
\hline Data are expressed as mean $\pm \mathrm{SD}$ (standard deviation).
\end{tabular}

Table 2. Definition of the Glasgow Prognostic Score (GPS)

\begin{tabular}{lc}
\hline \hline \multicolumn{1}{c}{ Variable } & GPS \\
\hline $\mathrm{hs}-\mathrm{CRP} \leq 10 \mathrm{mg} / \mathrm{L}$ and albumin $\geq 35 \mathrm{~g} / \mathrm{L}$ & 0 \\
$\mathrm{hs}-\mathrm{CRP}>10 \mathrm{mg} / \mathrm{L}$ & 1 \\
Albumin $\leq 35 \mathrm{~g} / \mathrm{L}$ & 1 \\
$\mathrm{hs}-\mathrm{CRP}>10 \mathrm{mg} / \mathrm{L}$ and albumin $\leq 35 \mathrm{~g} / \mathrm{L}$ & 2 \\
\hline $\mathrm{hs}-\mathrm{CRP}$ high sensitivity C-rive protein
\end{tabular}

hs-CRP, high sensitivity C-reactive protein.

by THOSHIBA 200FR (Toshiba medical system Co., Japan) and ADVIA CENTAUR XP (SIEMENS, USA) with absorption method and chemiluminescent microparticle immunoassay method, respectively. Relationships of GPS or PCT to the variables of study population were statistically assessed.

\section{Statistical analysis}

Data were presented as mean \pm standard deviation (SD). Relationships of GPS or PCT to the variables of study population were Pearson's correlation. Statistical significance was accepted with $P<0.05$.

\section{RESULTS}

\section{Demographic characteristics}

The demographic characteristics of the study population are shown in Table 1. A total of 135 patients (135 males, 27 females) were enrolled in this study. The cancer stage was on average $3.07 \pm 1.09$. The age distribution was $57.21 \pm$ 15.76 years.

\section{Hematological variables and blood coagulation}

The hematological variables of the study population are 
Table 3. Hematological variables of the study population

\begin{tabular}{lcc}
\hline \hline \multicolumn{1}{c}{ Variable } & Mean \pm SD & Reference value \\
\hline T-leukocyte $\left(10^{3} / \mu \mathrm{L}\right)$ & $7.96 \pm 3.15$ & $3.04 \sim 9.64$ \\
Neutrophil $(\%)$ & $52.38 \pm 22.68$ & $38.30 \sim 74.70$ \\
Lymphocyte $(\%)$ & $23.86 \pm 11.21$ & $21.20 \sim 51.00$ \\
Monocyte $(\%)$ & $10.03 \pm 5.29^{*}$ & $2.70 \sim 8.00$ \\
Eosinophil (\%) & $13.13 \pm 6.39^{*}$ & $0.20 \sim 8.40$ \\
Basophil (\%) & $8.14 \pm 7.37^{*}$ & $0.20 \sim 2.00$ \\
N/L ratio & $2.19 \pm 0.90^{*}$ & $1.46 \sim 1.79$ \\
RBC $(10 / \mu \mathrm{L})$ & $4.01 \pm 1.23$ & $3.78 \sim 5.52$ \\
Hematocrit $(\%)$ & $37.58 \pm 10.06$ & $35.60 \sim 51.10$ \\
Hemoglobin $(\mathrm{g} / \mathrm{dL})$ & $13.59 \pm 2.67$ & $10.80 \sim 17.20$ \\
MCV (fL) & $89.24 \pm 9.05$ & $85.00 \sim 102.50$ \\
MCHC (g/dL) & $32.70 \pm 1.92$ & $30.70 \sim 34.80$ \\
RDW (\%) & $16.84 \pm 2.30^{*}$ & $11.90 \sim 14.50$ \\
Platelet $\left(10^{3} / \mu \mathrm{L}\right)$ & $249.20 \pm 49.91$ & $148.00 \sim 361.00$ \\
P/L ratio & $131.05 \pm 29.36^{*}$ & $72.06 \sim 127.59$ \\
PDW $(\%)$ & $12.48 \pm 2.74$ & $9.80 \sim 16.20$ \\
MPV (fL) & $7.48 \pm 3.54^{*}$ & $9.40 \sim 12.60$ \\
\hline Dat &
\end{tabular}

Data are expressed as mean \pm SD. ${ }^{*}$, abnormal range.

T-total; N/L ratio, neutrophils to lymphocytes ratio; $\mathrm{RBC}$, red blood cells; MCV, mean corpuscular volume; MCHC, mean cell hemoglobin concentration; $\mathrm{P} / \mathrm{L}$ ratio, platelets to lymphocytes ratio; MPV, mean platelet volume; PDW, platelet distribution width; RDW, red cell distribution width.

shown in Table 3. Of the many parameters examined the monocyte, eosinophil basophil levels and red cell distribution width (RDW) levels, neutrophil/lymphocyte ration and the platelet/lymphocyte ratio were significantly higher in the study population were higher compared to the normal range. In contrast, the mean platelet volume (MPV) levels were significantly lower compared to the normal range. In the blood coagulation analysis, we found that the prothrombin time (PT) levels and D-dimer levels were higher than normal whereas the activated partial thromboplastin time (PTT) levels were within the normal range (Table 4).

\section{Biochemical analysis}

In the study population, blood glucose and sodium levels were lower in the study population compared to the normal range. In contrast, blood gamma-glutamyl transferase (GGT), total-bilirubin, creatinine and inorganic phosphorus concen-
Table 4. Coagulation variables of study population

\begin{tabular}{lcc}
\hline \multicolumn{1}{c}{ Variable } & Mean \pm SD & Reference value \\
\hline PT $(\mathrm{sec})$ & $9.60 \pm 1.24^{*}$ & $10.0 \sim 14.0$ \\
aPTT $(\mathrm{sec})$ & $20.49 \pm 8.84$ & $20.0 \sim 40.0$ \\
D-dimer $(\mathrm{mg} / \mathrm{L})$ & $1.41 \pm 1.24^{*}$ & $<0.55$
\end{tabular}

Data are expressed as mean \pm SD. ${ }^{*}$, abnormal range.

PT, prothrombin time; aPTT, activated partial thromboplastin time.

Table 5. Biochemical variables of the study population

\begin{tabular}{lcc}
\hline \hline \multicolumn{1}{c}{ Variable } & Mean $\pm \mathrm{SD}$ & $\begin{array}{c}\text { Reference } \\
\text { value }\end{array}$ \\
\hline T-protein (mg/dL) & $6.35 \pm 4.35$ & $6.70 \sim 8.30$ \\
Albumin (mg/dL) & $4.15 \pm 2.20$ & $3.20 \sim 4.30$ \\
Glucose (mg/dL) & $62.00 \pm 21.90^{*}$ & $70 \sim 99$ \\
AST (IU/L) & $16.81 \pm 19.68$ & $<37$ \\
ALT (IU/L) & $17.07 \pm 28.46$ & $<41$ \\
ALP (IU/L) & $52.15 \pm 51.93$ & $45 \sim 129$ \\
GGT (IU/L) & $171.08 \pm 40.32^{*}$ & $8 \sim 61$ \\
T-bilirubin (mg/dL) & $17.59 \pm 13.94^{*}$ & $0.01 \sim 1.20$ \\
BUN (mg/dL) & $15.34 \pm 14.15$ & $6 \sim 20$ \\
Creatinine (mg/dL) & $3.11 \pm 1.65^{*}$ & $0.60 \sim 1.20$ \\
Uric acid (mg/dL) & $2.06 \pm 2.22$ & $2.10 \sim 7.70$ \\
Inorganic phosphorus (mg/dL) & $5.49 \pm 5.21^{*}$ & $2.50 \sim 4.50$ \\
Sodium (mmol/L) & $110.45 \pm 23.87^{*}$ & $136 \sim 146$ \\
Potassium (mmol/L) & $4.46 \pm 3.13$ & $3.30 \sim 5.10$ \\
\hline
\end{tabular}

Data are expressed as mean \pm SD. ${ }^{*}$, abnormal range.

T, total protein; AST, aspartate aminotransferase; ALT, alanine aminotransferase, ALP, alkaline phosphatase; GGT, gammaglutamyl transferase; BUN, blood urea nitrogen.

trations were higher than normal (Table 5). We further examined various inflammatory and cardiac markers. We found that procalcitonin, high sensitivity $\mathrm{C}$-reactive protein (CRP) and Troponin-I (TNI) were detected at higher levels compared to normal (Table 6). Other variables were found to be within the normal range.

\section{Correlation of GPS and procalcitonin to demographic data}

We assessed whether the GPS and procalcitonin exhibited correlations with the demographic data from Table 1. We found a positive correlation of GPS to cancer stage $(P<$ 
Table 6. Inflammatory and cardiac markers of the study population

\begin{tabular}{lcc}
\hline \hline \multicolumn{1}{c}{ Variable } & Mean $\pm \mathrm{SD}$ & $\begin{array}{c}\text { Reference } \\
\text { value }\end{array}$ \\
\hline Procalcitonin $(\mathrm{ng} / \mathrm{mL})$ & $21.73 \pm 10.01^{*}$ & $<0.10$ \\
HS-CRP $(\mathrm{mg} / \mathrm{dL})$ & $5.84 \pm 3.11^{*}$ & $<0.50$ \\
Amylase $(\mathrm{IU} / \mathrm{L})$ & $14.11 \pm 13.24$ & $2.50 \sim 115$ \\
Lipase $(\mathrm{IU} / \mathrm{L})$ & $56.60 \pm 30.35$ & $<60$ \\
LDH $(\mathrm{U} / \mathrm{L})$ & $271.65 \pm 198.55$ & $240 \sim 480$ \\
BNP $(\mathrm{pg} / \mathrm{mL})$ & $9.73 \pm 4.80$ & $29 \sim 121$ \\
Troponin-I $(\mathrm{ng} / \mathrm{mL})$ & $8.27 \pm 6.56^{*}$ & $0.01 \sim 0.06$ \\
\hline
\end{tabular}

Data are expressed as mean \pm SD. ${ }^{*}$, abnormal range.

HS-CRP, high sensitivity C-reactive protein; BNP, brain natrieuretic peptide; $\mathrm{LDH}$, lactic dehydrogenase.

Table 7. The relationship of GPS or procalcitonin to demographic data of the study population

\begin{tabular}{lcc}
\hline \hline Variable & GPS $(r)$ & Procalcitonin $(r)$ \\
\hline Male & NS & NS \\
Female & NS & NS \\
Age & NS & NS \\
Body weight & NS & NS \\
Cancer stage & $0.32^{* * *}$ & NS \\
\hline
\end{tabular}

${ }^{* *}, P<0.001$.

Abbreviation: $r$, correlation coefficient; NS, not signifi cant.

0.001), but not to other variables such as gender, age nor body weight (Table 7). There were no statistically significant relationship between procalcitonin levels and all variables examined.

\section{Correlation of GPS and procalcitonin levels to hema-} tologic, coagulation, biochemical, inflammatory and cardiac markers

We investigated the correlation between GPS and various hematologic variables. We found that with the exception of one parameter (i.e. RBC counts), GPS either positively or negatively correlated with hematological variables to varying degrees (Table 8). In contrast, procalcitonin positively correlated only with RBC counts and hematocrit levels (Table 8 ). As for coagulation variables, GPS negatively correlated with PT or aPTT whereas procalcitonin shown no statistically significant correlation with PT, aPTT and D-dimer levels
Table 8. The relationship of GPS or procalcitonin to hematological variables

\begin{tabular}{lcc}
\hline \hline Variable & GPS $(r)$ & Procalcitonin $(r)$ \\
\hline T-leukocyte & $0.48^{* * *}$ & NS \\
Neutrophil & $-0.31^{* *}$ & NS \\
Lymphocyte & $-0.33^{* *}$ & NS \\
Monocyte & $0.45^{* * *}$ & NS \\
Eosinophil & $0.41^{* * *}$ & NS \\
Basophil & $0.42^{* * *}$ & NS \\
N/L ratio & $0.43^{* * *}$ & NS \\
RBC & NS & $0.69^{* * *}$ \\
Hematocrit & $-0.45^{* * *}$ & $0.23^{*}$ \\
Hemoglobin & $-0.31^{* *}$ & NS \\
MCV & $-0.48^{* * *}$ & NS \\
MCHC & $0.42^{* * *}$ & NS \\
RDW & $0.50^{* * *}$ & NS \\
Platelet & $-0.31^{* *}$ & NS \\
P/L ratio & $0.43^{* * *}$ & NS \\
PDW & $0.40^{* * *}$ & NS \\
MPV & $-0.39^{* * *}$ & NS \\
\hline
\end{tabular}

${ }^{*}, P<0.05 ;^{* *}, P<0.01 ;{ }^{* * *}, P<0.001$.

$r$, correlation coefficient; NS, not significant.

Table 9. The relationship of GPS or procalcitonin to coagulation variables

\begin{tabular}{lll}
\hline \hline Variable & GPS $(r)$ & Procalcitonin $(r)$ \\
\hline PT & $-0.54^{* * *}$ & NS \\
aPTT & $-0.38^{* * *}$ & NS \\
D-dimer & NS & NS \\
***,$P<0.001$. & \\
$r$, correlation coefficient; NS, not significant. &
\end{tabular}

(Table 9). GPS showed either a positive or negative relationship to albumin, glucose, AST, ALT, ALP, total bilirubin, BUN, uric acid, inorganic phosphorus and sodium levels whereas procalcitonin showed no statistically significant correlation with all the parameters examined (Table 10). Finally, we examined correlations between GPS and procalcitonin with the inflammatory and cardiac markers. We found that GPS negatively correlated with procalcitonin, hs-CRP, amylase, LDH, BNP and TNI. Additionally, procalcitonin levels positively correlated with amylase, BNP 
Table 10. The relationship of GPS or procalcitonin to biochemical variables

\begin{tabular}{lcc}
\hline \hline \multicolumn{1}{c}{ Variable } & GPS $(r)$ & Procalcitonin $(r)$ \\
\hline T-protein & $\mathrm{NS}$ & $\mathrm{NS}$ \\
Albumin & $-0.38^{* * *}$ & $\mathrm{NS}$ \\
Glucose & $-0.37^{* * *}$ & $\mathrm{NS}$ \\
AST & $0.27^{* * *}$ & $\mathrm{NS}$ \\
ALT & $0.20^{*}$ & $\mathrm{NS}$ \\
ALP & $0.23^{*}$ & $\mathrm{NS}$ \\
GGT & $\mathrm{NS}$ & $\mathrm{NS}$ \\
T-bilirubin & $0.36^{* * *}$ & $\mathrm{NS}$ \\
BUN & $0.20^{*}$ & $\mathrm{NS}$ \\
Creatinine & $\mathrm{NS}$ & $\mathrm{NS}$ \\
Uric acid & $-0.64^{* * *}$ & $\mathrm{NS}$ \\
Inorganic phosphorus & $0.53^{* * *}$ & $\mathrm{NS}$ \\
Sodium & $-0.4 .3^{* * *}$ & $\mathrm{NS}$ \\
Potassium & $\mathrm{NS}$ & $\mathrm{NS}$ \\
\hline
\end{tabular}

${ }^{*}, P<0.05 ;{ }^{* *}, P<0.01 ;{ }^{* * *}, P<0.001$.

$r$, correlation coefficient; NS, not significant.

and TNI (Table 11).

\section{DISCUSSION}

In the present study, GPS was found to significantly correlate with most variables, whereas procalcitonin correlated with a subset of the variables, suggesting that GPS is a more useful indicator than procalcitonin for evaluating and predicting lung cancer. Especially, GPS exhibited a positive correlation with cancer stage, indicating that advanced lung cancer can contribute to increased inflammation and aggravating symptoms. The detection of GPS is relatively easy and inexpensive and is a useful marker for assessing other cancers as well as lung cancer (Roxburgh et al., 2009; Nakayama et al., 2014; Tai et al., 2014; Platz et al., 2015). Lung cancer leads to interleukin-5 (IL-5) release and increase of eosinophil recruitment, resulting in infiltration, inflammation, allergic reaction in bronchopulmonary tissues, which generally leads to progression of disease (Huffnagle et al., 1998). Basophils are known to be involved in immediate hypersensitivity and cutaneous basophil hypersensitivity. Anthony (1982) demonstrated that basophil counts were
Table 11. The relationship of GPS or procalcitonin to inflammatory and cardiac markers

\begin{tabular}{lcc}
\hline \hline Variable & GPS $(r)$ & Procalcitonin $(r)$ \\
\hline Procalcitonin & $0.32^{* * *}$ & 1 \\
HS-CRP & $0.31^{* *}$ & $\mathrm{NS}$ \\
Amylase & $0.48^{* * *}$ & $0.29^{*}$ \\
Lypase & $\mathrm{NS}$ & $\mathrm{NS}$ \\
LDH & $0.20^{*}$ & $\mathrm{NS}$ \\
BNP & $0.56^{* * *}$ & $0.51^{* * *}$ \\
Troponin-I & $0.57^{* * *}$ & 0.48 \\
${ }^{*}, P<0.05{ }^{* *}, P<0.01 ;{ }^{* * *}, P<0.001$. & \\
$r$, correlation coefficient; $\mathrm{NS}$, not significant.
\end{tabular}

elevated in patients with squamous bronchial carcinoma and caused worse clinical conditions. Classical inflammatory monocytes and their derivative macrophages promote tumor metastasis (Cassetta and Pollard, 2015). We observed a positive relationship between GPS and monocytes, eosinophils and basophils but not procalcitonin, reflecting the importance of GPS for managing patients with lung cancer. This study shows negative correlation between GPS and neutrophils or lymphocytes. These findings suggest that decreased immunocompetence may occur with advanced lung cancer. Decreased immunocompetence can cause infections. The present study shows increased neutrophil/ lymphocyte and platelet/lymphocyte ratio, which are inflammatory indicators, and positive relationships with GPS. These data are considered to be useful clinical finding for predicting the severity of lung cancer (Kemal et al., 2014; Unal et al., 2015).

Cancer can lead to inflammation and inflammation seems to play a critical role in the development and progression of numerous cancers by promoting cancer cell proliferation and survival, angiogenesis, tumor metastasis and impacting tumor response to systemic therapies (Mantovani et al., 2008). Platelets play an important and multifaceted role in cancer progression. Platelets can promote tumor growth with increasing angiogenesis by the cytokine vascular endothelial growth factor (Dvorak et al., 1995). Kaplan et al. (1979) and Dubernard et al. (1997) also demonstrated that platelets can release growth factors such as platelet-derived growth factor, platelet factor 4 , and thrombospodin, which promote hema- 
togenesis spread, adhesion and invasion of tumor cells, and angiogenesis and to play an important role in tumor progression (Qian and Tuszynski, 1996). Recently, Oncel et al. (2015) reported that platelet distribution width (PDW) level was significantly higher, whereas mean platelet volume (MPV) level was lower in lung cancer group compared to the control group. We also found that PDW showed a positive correlation, while MPV had negative relationship to GPS.

These results may represent potential use of platelet indices in diagnosis and prediction of lung cancer. Several studies have shown that RDW is a strong predictor for the morbidity and mortality of all clinical cases, including cancers for (Perlstein et al., 2009; Patel et al., 2010; Albayrak et al., 2014). Our findings also show positive correlation between GPS and RDW which is in agreement with their results. However, platelet counts were negatively related with GPS. Previous studies have reported that platelet counts were elevated in lung cancer, including other cancers (Akinbami et al., 2013; Kim et al., 2014). Cancer cells secret neumerous humoral factors, which lead to throbocytosis and activation of coagulation system. Although it was compared with normal population, observations that platelet count was normal ranges and negative correlation to GPS may mean the development of DIC dissemenated intravascular coagulation (DIC), which is a pathological process characterized by the widespread activation of the clotting cascade that results in the formation of blood clots in the small blood vessels throughout the body. Increased D-dimer levels and negative relation to GPS in the present study support this possibility. D-dimer is a stable end product of fibrin degradation and its increase in blood reflects enhanced clotting cascade and fibrinolysis (Bick, 1992). Zhou et al. (2013) demonstrated that increased plasma D-dimer levels are associated with low mortality in lung cancer patients. Our and other data suggest that lung cancer can cause both coagulation and fibrinolytic system activations.

MPV was negatively related with GPS, indicating that increased GPS (inflammatory indicator) contribute to decrease of MPV, leading to worse consequence and low mortality (Oncel et al., 2015). On the other hand, most biochemical variables were significantly related with GPS, but not procalcitonin. Even though their levels were normal, albumin negatively correlated, while AST, ALT and ALP positively correlated with GPS suggesting that advanced lung cancer can lead to liver dysfunction (Proctor et al., 2013). Glucose and sodium levels were lower, while GGT, total bilirubin, creatinine and inorganic phosphorus levels were higher than their respective normal ranges. Decreased glucose concentration may attribute to patients' malnutrition. Hyponatremia is an electrolyte disorder commonly encountered in oncology practice. It is associated with lifethreatening neurological complications. Mild hyponatremia is defined as a serum sodium level $<135 \mathrm{mEq} / \mathrm{L}$, moderate $<132 \mathrm{mEq} / \mathrm{L}$, severe $<130 \mathrm{mEq} / \mathrm{L}$ and life-threatening $<125$ $\mathrm{mEq} / \mathrm{L}$ or abnormal sodium level with clinical signs (Palmer et al., 2003; Onitilo et al., 2007). In the present study, mean sodium concentration was $110.45 \pm 23.87 \mathrm{mEq} / \mathrm{L}$ and was negatively related GPS, suggesting that lung cancer can lead to severe hyponatremia and life-threatening neurological complications. Lung cancer-induced hyponatremia is due to abnormal secretion of anti-diuretic hormone (KarczmarekBorowska et al., 2014). Therefore, sodium levels, including other electrolytes should be controlled for lung cancer patients. Phosphorus level was higher than its normal range. Phosphorus is one of the most important elements in cells and organisms. Cell structure depends on phospholipids, energy production and storage depend on phosphorylated compounds, and the genetic information is contained in phosphate-containing DNA and RNA. Thus, phosphate is vital to normal physiological function and plays a role in intracellular signaling membrane function, energy metabolism, and bone mineralization (Sommer et al., 2007). A recent study reported that phosphorus and magnesium levels are predictive of disease in lung cancer patients, suggesting that phosphorus and magnesium levels may be important for stratifying patients to specific treatment protocols or intensifying their therapies (Kouloulias et al., 2015). Cancer cells that proliferate rapidly require a high amount of ribosome and other P-rich RNA components that are necessary to manufacture proteins (Kouloulias et al., 2015). Consequently it is a theoretical belief that tumor cells are richer in phosphorus than the surrounding tissue, and that they are promoting their metastasis due to their nutrient demands 
(De Carvalho and Caramujo, 2012). Phosphorus levels were positively related with GPS, meaning that increased inflammation attributable to lung cancer can result in elevated phosphorus concentrations and acceleration of metastasis. Procalcitonin, hs-CRP (inflammatory marker) and TNI (cardiac marker) levels were higher than their normal ranges, indicating the development of lung cancer-induced inflammation and age-induced potential coronary disease. Procalcitonin, hs-CRP, amylase, LDH, BNP and TNI levels positively correlated with GPS, suggesting that GPS can be a useful indicator for predicting other inflammatory and cardiovascular diseases, including lung cancer. In conclusion, our study suggest that GPS may be a potent and useful predictor for prognosis, therapeutic strategy, risk stratification and predicting long-term mortality of lung cancer.

\section{Acknowledgment}

This work was supported by the Brain Busan 21 Project in 2016.

\section{Conflict of interest}

The authors state that there is no conflict of interest.

\section{REFERENCES}

Akinbami A, Popoola A, Adediran A, Dosunmu A, Oshinaike O, Adebola P. Full blood count pattern of pre-chemotherapy breast cancer patients in Lagos, Nigeria. Caspian J Intern Med. 2013. 4: 574-579.

Albayrak S, Zengin K, Tanik S, Bakirtas H, Imamoglu A, Gurdal M. Red cell distribution width as a predictor of prostate cancer progression. Asian Pac J Cancer Prev. 2014. 15: 7781-7784.

Anthony HM. Blood basophils in lung cancer. Br J Cancer 1982. 45: 209-216.

Bick RL. Coagulation abnormalities in malignancy: a review. Semin Thromb Hemost. 1992. 18: 353-372.

Cassetta L, Pollard JW. Cancer immunosurveillance: role of patrolling monocytes. Cell Res. 2015. 144: Epub ahead of print.

de Carvalho CC1, Caramujo MJ. Tumour metastasis as an adaptation of tumor cells to fulfill their phosphorus requirements. Med Hypotheses. 2012. 78: 664-667.

Dubernard V, Arbeille BB, Lemesle MB, Legrand C. Evidence for an alpha-granular pool of the cytoskeletal protein alphaactinin in human platelets that redistributes with the adhesive glycoprotein thrombospondin-1 during the exocytotic process. Arterioscler Thromb Vasc Biol. 1997. 17: 2293-305.

Dumache R, Rogobete AF, Bedreag OH. Use of miRNAs as biomarkers in sepsis. Anal Cell Pathol (Amst). 2015. 2015: 186716.

Dvorak HF, Brown LF, Detmar M, Dvorak AM. Vascular permeability factor/vascular endothelial growth factor, microvascular hyperpermeability, and angiogenesis. Am J Pathol. 1995. 146: 1029-1039.

Huffnagle GB1, Boyd MB, Street NE, Lipscomb MF. IL-5 is required for eosinophil recruitment, crystal deposition, and mononuclear cell recruitment during a pulmonary Cryptococcus neoformans infection in genetically susceptible mice (C57BL/6). J Immunol. 1998. 160: 2393-2400.

Kaczka K, Mikosinski S, Fendler W, Celnik A, Pomorski L. Calcitonin and procalcitonin in patients with medullary thyroid cancer or bacterial infection. Adv Clin Exp Med. 2012. 21: 169-178.

Kaplan KL, Broekman MJ, Chernoff A, Lesznik GR, Drillings M. Platelet alpha-granule proteins: studies on release and subcellular localization. Blood 1979. 53: 604-618.

Karczmarek-Borowska B, Zielińska K, Bukała A. Hyponatremia in the course of small cell lung cancer-a case report. Pol Merkur Lekarski. 2014. 37: 49-52.

Kemal Y, Yucel I, Ekiz K, Demirag G, Yilmaz B, Teker F. Elevated serum neutrophil to lymphocyte and platelet to lymphocyte ratios could be useful in lung cancer diagnosis. Asian Pac J Cancer Prev. 2014. 15: 2651-2654.

Kim KH, Park TY, Lee JY, Lee SM, Yim JJ, Yoo CG. Prognostic significance of initial platelet counts and fibrinogen level in advanced non-small cell lung cancer. J Korean Med Sci. 2014. 29: 507-511.

Kouloulias V, Tolia M, Tsoukalas N, Papaloucas C, PistevouGombaki K, Zygogianni A. Is there any potential clinical impact of serum phosphorus and magnesium in patients with lung cancer at first diagnosis? A multi-institutional study. Asian Pac J Cancer Prev. 2015. 16: 77-81.

Lee NK, Kim HS. Tumor induces expansion of FoxP $3^{+} \mathrm{CD} 25^{\text {high }}$ and $\mathrm{CD} 11 \mathrm{~b}^{+} \mathrm{Gr} 1^{+}$cell population in the early phase of tumor progression. Biomed Sci Lett. 2015. 21: 172-180.

Liu HH, Guo JB, Geng Y, Su L. Procalcitonin: present and future. Ir J Med Sci. 2015. 184: 597-605.

Mantovani A, Allavena P, Sica A, Balkwill F. Cancer-related in- 
flammation. Nature. 2008. 454: 436-444.

Maruna P, Nedelnikova K, Gurlich R. Physiology and genetics of procalcitonin. Physiol Res. 2000. 49(Suppl 1): S57-S61.

Matzaraki V, Alexandraki KI, Venetsanou K. Evaluation of serum procalcitonin and interleukin-6 levels as markers of liver metastasis. Clin Biochem. 2007. 40: 336-342.

McMillan DC. The systemic inflammation-based Glasgow Prognostic Score: a decade of experience in patients with cancer. Cancer Treat Rev. 2013. 39: 534-540.

McDonald B, Spicer J, Giannais B, Fallavollita L, Brodt P, Ferri LE. Systemic inflammation increases cancer cell adhesion to hepatic sinusoids by neutrophil mediated mechanisms. Int $\mathbf{J}$ Cancer. 2009. 125: 1298-1305.

Nakayama M, Tabuchi K, Hara A. Clinical utility of the modified Glasgow Prognostic Score in patients with advanced head and neck cancer. Head Neck. 2014. 10: 23-28.

Oncel M, Kiyici A, Oncel M, Sunam GS, Sahin E, Adam B. Evaluation of platelet indices in lung cancer patients. Asn Pac J Cancer Prev. 2015. 6: 7599-702.

Onitilo AA, Kio E, Doi SA. Tumor-related hyponatremia. Clin Med Res. 2007. 5: 228-237.

Palmer BF1, Gates JR, Lader M. Causes and management of hyponatremia. Ann Pharmacother. 2003. 37: 1694-1702.

Patel KV, Semba RD, Ferrucci L. Red cell distribution width and mortality in older adults: a meta-analysis. J Gerontol A Biol Sci Med Sci. 2010. 65: 258-265.

Patout M, Salaun M, Brunel V, Bota S, Cauliez B, Thiberville L. Diagnostic and prognostic value of serum procalcitonin concentrations in primary lung cancers. Clin Biochem. 2014. 47: 263-267.

Perlstein TS, Weuve J, Pfeffer MA. Red blood cell distribution width and mortality risk in a community-based prospective cohort. Arch Intern Med. 2009. 169: 588-594.

Platz E, Jhund PS, Campbell RT, McMurray JJ. Assessment and prevalence of pulmonary oedema in contemporary acute heart failure trials: a systematic review. Eur J Heart Fail. 2015. 17: 906-916.

Proctor MJ, Horgan PG, Talwar D, Fletcher CD, Morrison DS,
McMillan DC. Optimization of the systemic inflammationbased Glasgow prognostic score: a Glasgow inflammation outcome study. Cancer. 2013. 119: 2325-2332.

Qian X, Tuszynski GP. Expression of thrombospondin-1 in cancer: a role in tumor progression. Proc Soc Exp Biol Med. 1996. 212: 199-207.

Rast AC, Kutz A, Felder S, Faessler L, Steiner D, Laukemann S, Haubitz S, Huber A, Buergi U, Conca A, Reutlinger B, Mueller B, Bargetzi M, Schuetz P. Procalcitonin improves the Glasgow Prognostic Score for outcome prediction in emergency patients with cancer: a cohort study. Dis Markers 2015. 2015: 795801.

Roxburgh CS, Crozier JE, Maxwell F, Foulis AK, Brown J, McKee RF. Comparison of tumour-based (Petersen Index) and inflammation-based (Glasgow Prognostic Score) scoring systems in patients undergoing curative resection for colon cancer. Br J Cancer 2009. 100: 701-706.

Shackelford RE, Vora M, Mayhall K, Cotelingam J. ALKrearrangements and testing methods in non-small cell lung cancer: a review. Genes Cancer. 2014. 5: 1-14.

Singh PP, Zeng ISL, Srinivasa S. Systematic review and metaanalysis of use of serum C-reactive protein levels to predict anastomotic leak after colorectal surgery. Br J Surg. 2014. 101: 339-346.

Sommer S, Berndt T, Craig T, Kumar R. The phosphatonins and the regulation of phosphate transport and vitamin D metabolism. J Steroid Biochem Mol Biol. 2007. 103: 497-503.

Tai CG, Johnson TV, Abbasi A, Herrell L, Harris WB, Kucuk O. External validation of the modified Glasgow prognostic score for renal cancer. Indian J Urol. 2014. 30: 33-37.

Tenesa A, Theodoratou E, Din FV, Farrington SM, Cetnarskyj R, Barnetson RA, Porteous ME, Campbell H, Dunlop MG. Ten common genetic variants associated with colorectal cancer risk are not associated with survival after diagnosis. Clin Cancer Res. 2010. 16: 3754-3479.

Unal D, Eroglu C, Kurtul N, Oguz A, Tasdemir A. Are neutrophil/ lymphocyte and platelet/lymphocyte rates in patients with non-small cell lung cancer associated with treatment response and prognosis? Asian Pac J Cancer Prev. 2013. 14: 5237-5242. 